\title{
Changes in Enzyme Activity and Bacterial Succession During Sewage Sludge Composting
}

\author{
Chuang Ma*, Hui-jia Jin*, Bin Hu*, Nan Liu*, Ke Zhang*, Ji-hong Zhao** and Hong-zhong Zhang**† \\ *Zhengzhou University of Light Industry, Zhengzhou 450001, PR China \\ **Collaborative Innovation Center of Environmental Pollution Control and Ecological Restoration, Henan Province, \\ Zhengzhou 450001, PR China \\ $\nmid$ Corresponding author: Hong-zhong Zhang (E-mail: Chuang Ma; machuang819@qq.com)
}

Nat. Env. \& Poll. Tech.

Website: www.neptjournal.com

Received: 24-07-2019

Accepted: 08-10-2019

Key Words:

Bacteria;

Composting;

Correlation;

Enzyme activity;

Sewage sludge

\begin{abstract}
To study the variations in microorganisms and enzyme activity during sewage sludge composting, the dynamic changes in temperature, enzyme activity and microorganism composition were studied by co-composting municipal sludge and corn straw. The results show that the pile underwent mesophilic, thermophilic, and cooling phases and that the high-temperature duration $\left(\geq 50{ }^{\circ} \mathrm{C}\right)$ had reached 5 days, which meets harmlessness requirements. During the composting process, the protease, arylsulfatase (ARS) and cellulase content increased gradually; urease content first decreased and then increased rapidly; and peroxidase (POD) content first increased and then decreased. Ureibacillus, Bacillus, Pseudomonas, Flavobacterium and Sporosarcina were the dominant bacteria during sludge composting. Microorganisms played different roles at different stages of the composting. Ureibacillus and Bacillus were the dominant strains in the mesophilic and thermophilic phases, respectively, and Pseudomonas and Flavobacterium were the dominant strains in the cooling phase. Sporosarcina mainly played a role later in the thermophilic and cooling phases. The effect of different bacteria on enzyme activity varied; Pseudomonas played a clear role in promoting the production of urease while Bacillus had a clear inhibitory effect on the production of urease. Ureibacillus inhibited the production of ARS, POD, protease and cellulase. By studying the changes in microbial and enzymatic activities at different stages of sludge composting, it is possible to thoroughly explore the nature of the latter and provide a reference for optimizing composting processes.
\end{abstract}

\section{INTRODUCTION}

Sewage sludge is a by-product of municipal wastewater treatment plants that is rich in organic matter, nitrogen, phosphorus and other nutrients, and qualified sludge compost is a high-quality soil amendment (Ma et al. 2018). Composting is the process of converting organic waste into stable humus through microbial activities, which are largely influenced by $\mathrm{C} / \mathrm{N}$, moisture content, temperature, $\mathrm{pH}$ and ventilation conditions (Du et al. 2019). In composting, microorganisms are the main players in various organic metabolic activities, but their main function is the biochemical decomposition of degradable organic matter through enzymatic action (Langarica-Fuentes et al. 2014). Bacteria are the main microbial population that decompose organic matter and produce heat during composting. Their diversity and abundance directly affect the composting process (Vieira et al. 2019). Microorganisms promote the mineralization and decomposition of organic matter by secreting extracellular enzymes (Geisseler et al. 2008, Becarelli et al. 2019). For example, degradable organic matter (starch and sugars) and refractory organic matter (cellulose and lignin) are gradually mineralized and decomposed under the action of various specific enzymes, but the activities of these enzymes are closely related to the composition of bacterial communities. Composting cannot occur without the work of a series of specific functional enzymes such as protease, urease, and peroxidase (POD) (Krajewska et al. 2009, Du et al. 2018). Cellulase plays a major role in the degradation of cellulose to glucose and POD is related to lignin degradation. Both enzymes contribute to the degradation of organic matter and the carbon cycle (He et al. 2013). Protease and urease are involved in the nitrogen cycle during composting processes, while arylsulfatase (ARS) is involved in the sulphur cycle (Zeng et al. 2010). The sulphur cycle is closely related to the main odorous substances $\left(\mathrm{NH}_{3}\right.$ and $\left.\mathrm{H}_{2} \mathrm{~S}\right)$ produced during composting. Enzyme activities are also closely related to microbial composition and activity in the different stages of composting. Microbial composition analysis during mesophilic, thermophilic, and cooling phases can help us understand the nature of composting more thoroughly.

Little attention has been paid, to date, to the dynamic changes in the functional enzymes in aerobic sludge com- 
posting, and the relationship between the composition and structure of bacteria and functional enzyme activity at different stages of fermentation (Krajewska et al. 2009, He et al. 2013). Therefore, temperature and enzyme content analysis of different fermentation stages in sludge composting, and modern high-throughput sequencing methods, can be used to obtain a thorough understanding of the changes in enzyme activity and bacterial community structure. This can lead to a comprehensive understanding of the evolution of microbial communities and the degradation of organic matter during the composting process.

\section{MATERIALS AND METHODS}

\section{Composting Material and Technology}

Dewatered sludge was collected from a domestic sewage treatment plant in Zhengzhou City. The water content was $80.8 \%$ and the volatile organic compound (VOC) content was $54.8 \%$. Corn straw was used as the auxiliary material. The particle size was $1-2 \mathrm{~cm}$, the moisture content was $9.27 \%$, and the VOC content was $87.27 \%$.

The dewatered sludge and corn straw were evenly mixed in a 3:1 weight ratio and then fermented by static stacking and high-temperature aerobic composting. The VOC content was $80.31 \%$ and the heap bulk density was $570.46 \mathrm{~kg} \cdot \mathrm{m}^{3}$.

The fermentation reactor was $1.2 \mathrm{~m}$ high and $0.6 \mathrm{~m}$ in diameter. There was a ventilation system at the bottom of the fermentation reactor. Forced ventilation was controlled by an automatic blower. The ventilation interval was $12-15$ min and the duration of the blast (regulated and controlled by a computer according to the fermentation temperature feedback) was 1-3 min.

\section{Sampling and Analysis Method}

Based on the composting temperature, $1 \mathrm{~kg}$ of compost (from $30 \mathrm{~cm}$ under the surface layer of the compost body) was sampled in a sealed bag during the mesophilic phase (days 1 and 3), thermophilic phase (days 5 and 7), and cooling phase (day 10) and then taken to the laboratory for analysis. The temperature of the sludge fermentation process was monitored automatically with a temperature probe. Protease content was determined by ninhydrin colourimetry, urease activity was determined by sodium phenol-sodium hypochlorite colourimetry (Nannipieri et al. 2002), and ARS content was determined by sodium hydroxide-calcium chloride colourimetry (Tabatabai et al. 1970). POD content was determined by pyrogallol colourimetry and cellulase content was determined by 3,5-Dinitrosalicylic acid colourimetry.

The compost samples were sent to Shanghai Meiji Biomedical Technology Co., Ltd. for high-throughput sequencing. Microbial DNA was extracted with a soil FastDNA Spin Kit (MPBio) method. The DNA was purified and determined using a NanoDrop 2000 ultraviolet-visible spectrophotometer (Thermo Scientific, Wilmington, USA). The v3-v4 hypervariable region of the $16 \mathrm{~S}$ rRNA gene was amplified with primers 338F (ACTCCTGGGAGGCGAGCGAG) and 806R (GGACTACHVGGTWTCTAAT).

\section{Statistical Analysis}

SPSS (V 19.0) was used for statistical analysis, the Duncan method was used for multiple comparisons, and Origin 9.0 was used to draw charts.

\section{RESULTS AND DISCUSSION}

\section{Dynamic Change of Temperature During Sewage}

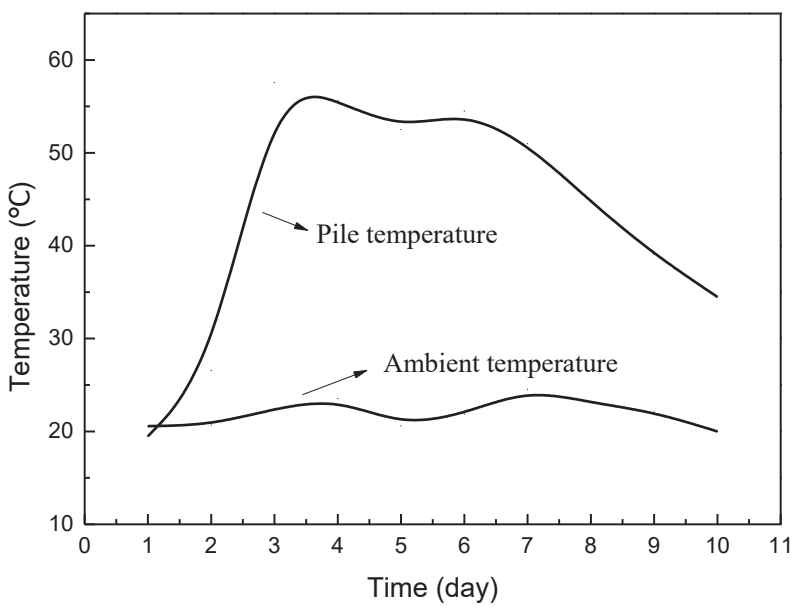

Fig. 1: Changes in pile temperature during composting. 


\section{Sludge Composting}

During aerobic composting of sewage sludge, microorganisms (through enzymatic action) decompose organic matter and heat is released (He et al. 2013). The composting temperature is thus influenced by microbial activity and material oxidation. The decomposition of organic matter is accompanied by the rise and fall of composting temperature so that the composting material can be matured and harmless. As illustrated in Fig. 1, the ambient temperature fluctuated around $20^{\circ} \mathrm{C}$ throughout the composting process and the sludge and straw composting process lasted for 10 days. The heap experienced mesophilic (day 1-3), thermophilic (day 4-7) and cooling (day 8-10) phases. The reactor temperature began to rise on day 1 and reached its highest temperature of $57.6^{\circ} \mathrm{C}$ on day 3 , with a heating rate of $12.7^{\circ} \mathrm{C} /$ day. The thermophilic phase (temperature $>50^{\circ} \mathrm{C}$ ) duration of the compost was approximately 5 days, which meets the hygienic index of composting and effectively kills pathogenic bacteria and weed seeds in the compost (Zeng et al. 2010).

\section{Dynamic Changes of Enzyme Activities in Sludge Composting Process}

Corn straw, which can be classified as microbial refractory organic matter, has high cellulose content, a complex structure, and is difficult to degrade (Vieira et al. 2019). It is usually degraded by POD and polyphenol oxidase. As illustrated in Fig. 2(a), POD activity increased gradually and then decreased significantly $(\mathrm{P}<0.05)$ during composting. POD content was significantly higher during the high-temperature phase than in the heating and cooling periods, reaching a maximum value of $192.50 \mu \mathrm{mol} / \mathrm{h}$.g on day 7 . The higher POD levels were due to the high population and activity of microorganisms during the high-temperature period, which thus meant that more POD was produced to promote the degradation of cellulose, lignin, and other refractory organic matter.

Hydrolytic enzymes are key enzymes in organic mineralization during composting (Du et al. 2019). Their activity can be used to characterize the degradation efficiency of organic matter (Krajewska et al. 2009). Protease and urease are closely related to the nitrogen cycle in composting and are important functional enzymes. During sludge composting, protease activity increased gradually (Fig. 2(b)), and reached a maximum of $3.25 \mathrm{mg} / \mathrm{g}$ on day 10 . The urease content first decreased and then increased, and reached a maximum of $1.90 \mathrm{mg} / \mathrm{g}$ at the end of composting (Fig. 2(c)). The urease content in the cooling phase was significantly higher than in the mesophilic and thermophilic phases, while the urease content was significantly higher in the mesophilic phase than in the thermophilic phase $(\mathrm{P}<0.05)$.
Cellulose-decomposing bacteria degrade corn straw cellulose by secreting cellulase. During sludge composting, the cellulase content increased gradually $(\mathrm{P}<0.05)$ and reached a maximum of $335.79 \mu \mathrm{g} / \mathrm{g} * \mathrm{~min}$ at the end of composting (Fig. 2(d)). This is consistent with the conclusion that cellulase activity increased gradually during the composting of chicken, pig, and cow manure. This finding is also consistent with the fact that cellulose is a relatively refractory organic matter and that its degradation occurs mainly in the middle and late stages of composting (Becarelli et al. 2019). ARS is mainly involved in the conversion of organic sulphur to $\mathrm{SO}_{4}{ }^{2-}$ (Toledo et al. 2018). As illustrated in Fig. 2(e), the ARS activity increased steadily and continuously. The ARS activity during the cooling phase (days 7-10) was significantly higher $(\mathrm{P}<0.05)$ than during the mesophilic and thermophilic phases. This may be due to the gradual release of organic sulphur from straw with the degradation of cellulose and other refractory organic matter (Toledo et al. 2018).

\section{Dynamic Changes of Microbial Composition in Sludge Composting Process}

Coverage reflects whether the sequencing results represent the true situation of microorganisms in the samples. Here, the mesophilic, thermophilic and cooling phases reached 0.9956 , 0.9956 and 0.9973 , respectively (Table 1 ), which indicated that the sequencing results were highly representative (Ye et al. 2017). Bacterial composition varied during sludge composting, and the richness and diversity of the bacterial community are different at different fermentation stages (Table 1). Sobs, Ace and Chao are all indicators of microbial community richness (Ke et al. 2018). From Table 1, we can see that Sobs, Ace and Chao decreased, respectively, from $573,655.40$ and 651.54 in the mesophilic phase (day 3) to 407, 531.21 and 535.82 in the thermophilic phase (day 5), and then to $325,379.08$ and 374.91 in the cooling phase (day 10). Shannon is an index reflecting microbial community diversity (Huang et al. 2013), which decreased from 3.62 in the mesophilic phase (day 3) to 3.47 in the thermophilic phase (day 5) and then to 2.97 in the cooling phase (day 10) (Table 1). This indicated that the richness and diversity of the microbial community decreased with composting. This may be due to the abundant degradable organic matter such as sugars in the raw material during the early stage of composting, which resulted in higher bacteria richness in the mesophilic phase compared to the thermophilic and cooling phases.

The dominant bacteria in the composting process were Ureibacillus, Bacillus, Pseudomonas, Flavobacterium and Sporosarcina (Fig. 3). The proportion of Ureibacillus in the bacterial community decreased with time. The proportion of Ureibacillus decreased rapidly from $37.9 \%$ in the mesophilic 
phase to $3.82 \%$ in the thermophilic phase, and then to $0.48 \%$ in the cooling phase. The proportion of Ureibacillus in the mesophilic phase was significantly higher than in the thermophilic and cooling phases. This indicates that it was the dominant bacteria in the mesophilic phase and played a major role during this stage of composting (Vieira et al. 2019). The proportion of Bacillus in the community first increased and then decreased. The proportion of Bacillus increased rapidly from $11.50 \%$ in the mesophilic phase to $31.58 \%$ in the thermophilic phase and then decreased rapidly to $1.66 \%$ in the cooling phase. The proportion of Bacillus in the thermophilic phase was the largest; significantly higher than in the mesophilic and cooling phases. This indicated that Bacillus was the dominant bacteria in the thermophilic phase and played a major role in this composting phase. Pseudomonas increased from an extremely low proportion of the bacterial community in the mesophilic and thermophilic phases to $36.69 \%$ in the cooling phase, which indicated that Pseudomonas played a major role in the cooling phase of the composting process and was the dominant bacteria during this period. The proportion of Sporosarcina in the bacterial community increased rapidly during the composting process, from $0 \%$ in the mesophilic phase to $3.88 \%$ and $9.81 \%$ in the thermophilic and cooling phases, respectively, which indicated that Sporosarcina played a role in the thermophilic and cooling phases of the composting process (Du et al. 2019).

\section{Correlation between Dominant Bacteria and Functional Enzyme Activity in Sludge Composting Process}

The Heatmap diagram clearly shows the relationship between functional enzyme activity and functional microorganisms. As illustrated in Fig. 4, urease was positively correlated with Pseudomonas ( $\mathrm{r}=1, \mathrm{P}=0$ ), indicating that Pseudomonas played a significant role in promoting the production of urease (Vieira et al. 2019). There was a significant negative correlation between urease and Bacillus $(\mathrm{r}=-1, \mathrm{p}=0)$, indicating that Bacillus had a significant inhibitory effect on urease production, which is consistent with the minimum urease activity in the thermophilic phase and the maximum urease activity in the cooling phase (Fig. 2). There was a significant
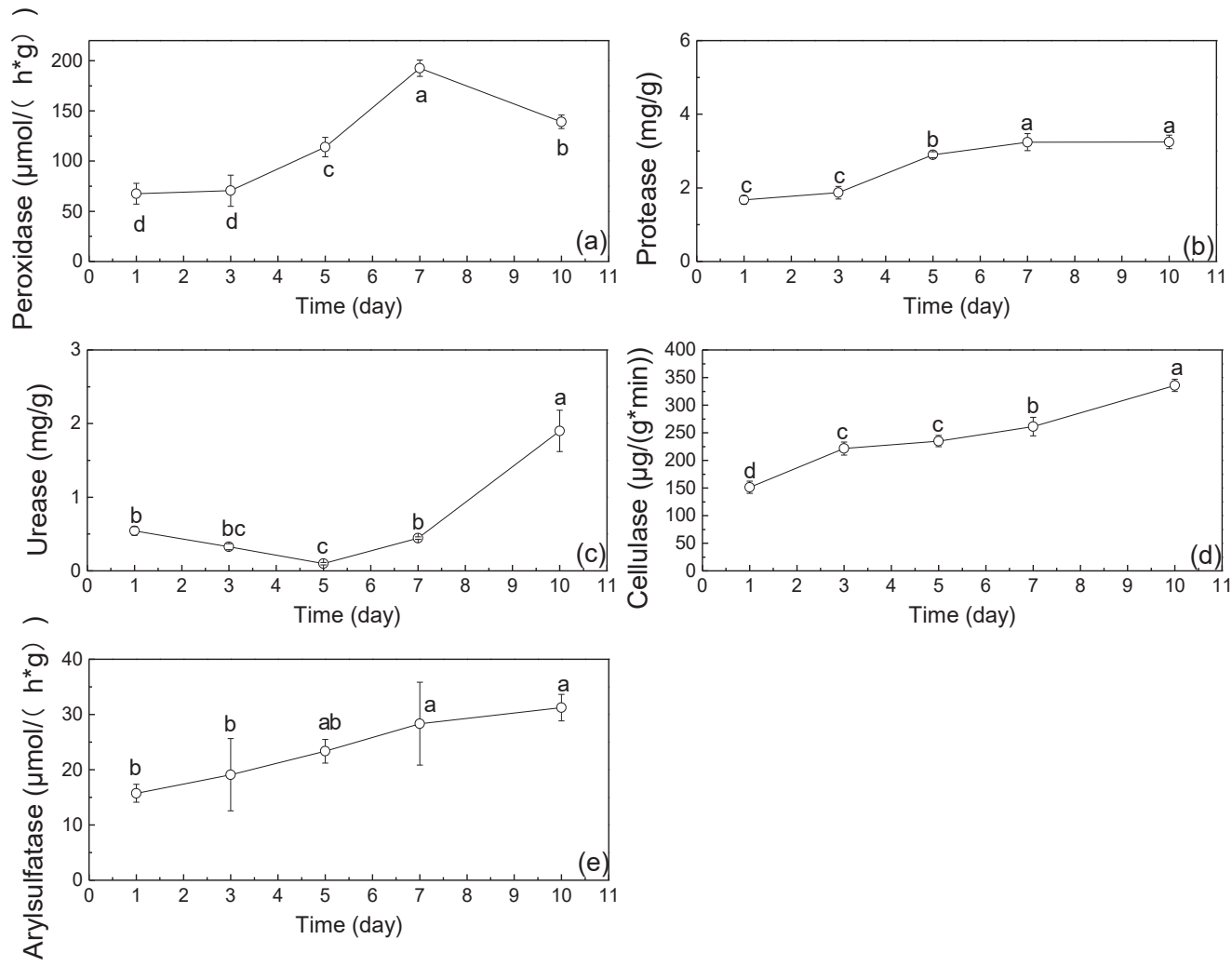

Fig. 2: Evolution of enzyme activities of different piles during composting.

Note: Different letters indicate significant difference at $\mathrm{P}<0.05$ among different samples. 
negative correlation between ARS and Ureibacillus ( $\mathrm{r}=-1$, $\mathrm{p}=0$ ). This indicates that Ureibacillus had a significant inhibitory effect on ARS production. ARS is an important enzyme involved in the sulphur cycle of composting materials. It can be inferred that Ureibacillus can inhibit the degradation of organic sulphur during the heating period. There was a significant negative correlation between POD and Ureibacillus ( $\mathrm{r}=-1, \mathrm{p}=0$ ), indicating that Ureibacillus had a significant inhibitory effect on POD production. This finding was the most consistent with POD activity in the later thermophilic phase (Du et al. 2019). There was a significant negative correlation between protease and Ureibacillus $(\mathrm{r}=-1, \mathrm{p}=0)$, indicating that Ureibacillus had a significant inhibitory effect on protease production. This was also consistent with the maximum activity of protease during the cooling phase. There was a significant negative correlation between cellulase and Ureibacillus $(\mathrm{r}=-1, \mathrm{p}=0)$, indicating that Ureibacillus had a significant inhibitory effect on cellulase production. This was also consistent with the fact that cellulose is a relatively refractory organic

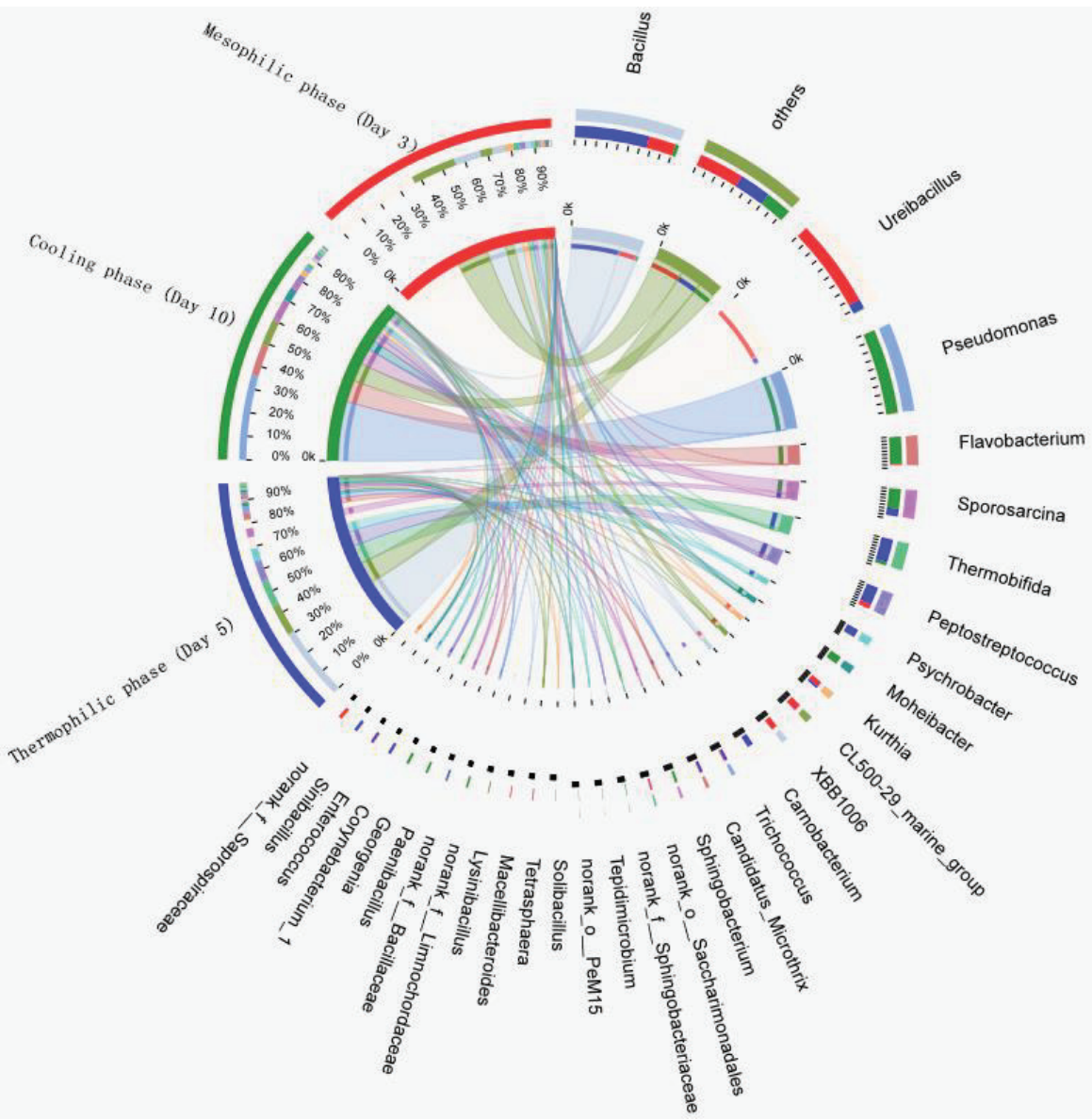

Fig. 3: Distribution of bacterial community compositions at different composting stages.

Table 1: Bacterial diversity indices during sewage sludge composting.

\begin{tabular}{|llllll|}
\hline Fermentation stage & Sobs & Shannon & Ace & Chao & Coverage \\
\hline Mesophilic phase (Day 3) & 573 & 3.62 & 655.40 & 651.54 & 0.9956 \\
Thermophilic phase (Day 5) & 407 & 3.46 & 531.21 & 535.82 & 379956 \\
Cooling phase (Day 10) & 325 & 2.97 & 379.08 & 0.9973 \\
\hline
\end{tabular}




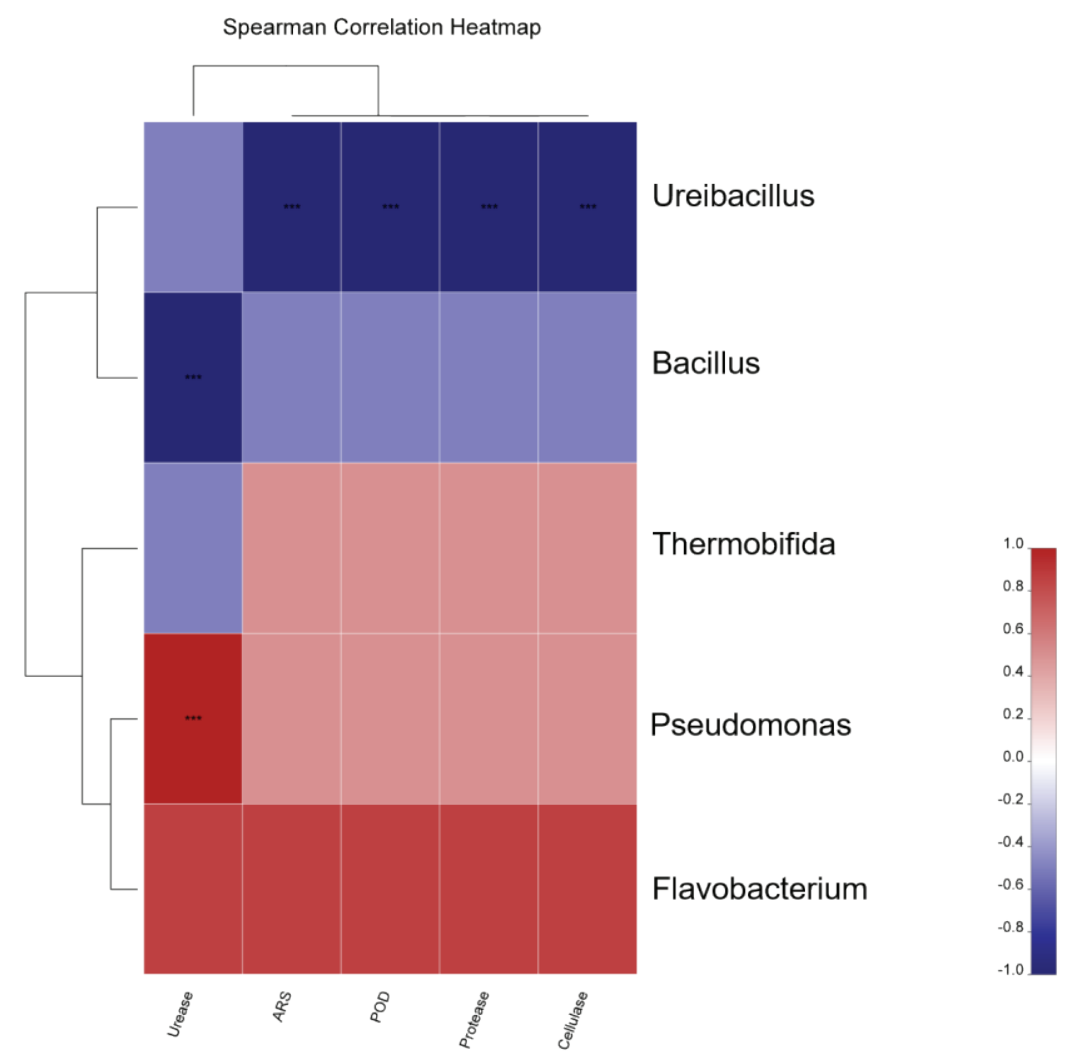

Fig. 4: Correlation between enzyme activity and bacteria in sludge composting process.

matter, and its degradation process mainly occurs in the late stage of composting (Becarelli et al. 2019).

\section{CONCLUSION}

The composting of corn straw and sludge experienced mesophilic, thermophilic and cooling phases, and the thermophilic duration (temperature $>50^{\circ} \mathrm{C}$ ) reached 5 days, which meets the harmlessness requirement. During the composting process, protease, ARS and cellulase increased gradually, urease content first decreased and then increased rapidly, and POD activity first increased and then decreased. Ureibacillus, Bacillus, Pseudomonas, Flavobacterium and Sporosarcina were the dominant bacteria in the sludge composting process. Microorganisms played different roles in different fermentation stages. Among them, Ureibacillus was the dominant bacteria in the mesophilic phase, and Bacillus was the dominant bacteria in the thermophilic phase. Pseudomonas and Flavobacterium were the dominant bacteria in the cooling phase, while Sporosarcina also mainly occurred and played a role in the cooling phase. Different bacteria have different effects on different enzymes in sludge composting. Pseudomonas can promote urease, while Bacillus can inhibit urease. Ureibacillus had a clear inhibitory effect on ARS, $\mathrm{POD}$, protease and cellulase.

\section{ACKNOWLEDGEMENTS}

This research was financially supported by the National Natural Science Foundation of China (No.41501527), and the Zhengzhou University of Light Industry (Grant No. 2013BSJJ022).

\section{REFERENCES}

Becarelli, S., Chicca, I., Siracusa, G., La China, S., Gentini, A., Lorenzi, R., Munz, G., Petroni, G., Levin, D.B. and Di Gregorio, S. 2019. Hydrocarbonoclastic Ascomycetes to enhance co-composting of total petroleum hydrocarbon (TPH) contaminated dredged sediments and lignocellulosic matrices. New Biotechnology, 50: 27-36.

Du, J.J., Zhang, Y.Y., Qu, M.X., Yin, Y.T., Fan, K., Hu, B., Zhang, H.Z., Wei, M.B. and Ma, C. 2018. Effects of biochar on the microbial activity and community structure during sewage sludge composting. Bioresource Technology, 272: 171-179.

Geisseler, D. and Horwath, W. R. 2008. Regulation of extracellular protease activity in soil in response to different sources and concentrations of nitrogen and carbon. Soil Biology \& Biochemistry, 40(12): 3040-3048.

He, Y., Xie, K., Xu, P., Huang, X., Gu, W., Zhang, F. and Tang, S. 2013. Evolution of microbial community diversity and enzymatic activity during composting. Research in Microbiology, 164(2): 189-198. 
Huang, K., Li, F., Wei, Y., Chen, X. and Fu, X. 2013. Changes of bacterial and fungal community compositions during vermicomposting of vegetable wastes by Eisenia foetida. Bioresource Technology, 150(4): 235-241.

Ke, W., Hailong, M., Zhe, W. and Yu, T. 2018. Succession of organics metabolic function of bacterial community in swine manure composting. Journal of Hazardous Materials, 360: 471-480.

Krajewska, Barbara. 2009. Ureases I. Functional, catalytic and kinetic properties: A review. Journal of Molecular Catalysis B Enzymatic, 59(1): 9-21.

Langarica-fuentes, A., Handley, P.S., Houlden, A., Fox, G. and Robson, G.D. 2014. An investigation of the biodiversity of thermophilic and thermotolerant fungal species in composts using culture-based and molecular techniques. Fungal Ecology, 11: 132-144.

Ma, C., Liu, F.Y., Wei, M.B., Du, J.J., Liu, N. and Zhang, H.Z. 2018. Effects of initial moisture content on phenanthrene degradation behavior during sludge composting. Nature Environment and Pollution Technology, 17(4): 1167-1173.

Nannipieri, P., Kandeler, E., Ruggiero, P., Burns, R.G. and Dick, R.P. 2002. Enzyme activities and microbiological and biochemical processes in soil. In: Enzymes in the Environment. Marcel Dekker, New York, pp. 1-33.
Tabatabai, M. and Bremner, J. 1970. Arylsulfatase activity of soils. Soil Science Society of America Journal, 34(2): 225- 229.

Toledo, M., Gutiérrez, M.C., Siles, J. A. and Martín, M.A. 2018. Full-scale composting of sewage sludge and market waste: Stability monitoring and odor dispersion modeling. Environmental Research, 167: 739-750.

Vieira, F. R., Pecchia, J. A., Segato, F. and Polikarpov, I. 2019. Exploring oyster mushroom (Pleurotus ostreatus) substrate preparation by varying phase I composting time: changes in bacterial communities and physicochemical composition of biomass impacting mushroom yields. Journal of Applied Microbiology, 126: 931-944.

Ye, J., Joseph, S.D., Ji, M., Nielsen, S., Mitchell, D.R.G., Donne, S., Horvat, J., Wang, J., Munroe, P. and Thomas, T. 2017. Chemolithotrophic processes in the bacterial communities on the surface of mineral-enriched biochars. The ISME Journal, 11(5): 1087-1101.

Zeng, G.M., Yu, M., Chen, Y.N., Huang, D.L., Zhang, J.C., Huang, H.L., Jiang, R.Q. and Yu, Z. 2010. Effects of inoculation with Phanerochaete chrysosporium at various time points on enzyme activities during agricultural waste composting. Bioresource Technology, 2101(1): 222-227. 